\title{
EFFICACY AND SAFETY OF MAXILLARY SINUS LIFTING WITH VARIOUS TYPES OF GRAFTING WITH IMPLANTS INSERTION PURPOSES: A REVIEW OF THE LITERATURE
}

\section{ORIGINAL ARTICLE}

JÚNIOR, João de Paula Martins ${ }^{1}$

ATALLAH, Álvaro Nagib ${ }^{2}$

JÚNIOR, João de Paula Martins. ATALLAH, Álvaro Nagib. Efficacy and safety of maxillary sinus lifting with various types of grafting with implants insertion purposes: A review of the literature. Multidisciplinary Scientific Journal Knowledge Nucleus. Year 05, Ed. 03, Vol. 07, pp. 31-45. March 2020. ISSN:2448-0959, Access link in: https://www.nucleodoconhecimento.com.br/dentistry/efficacy-and-safety

\section{ABSTRACT}

Context: Edentulous patients under the use of removable prosthesis face important restrictions, including sociocultural ones and, for this reason, the insertion of implants has become frequent in clinical dental practice. However, the success of the method will depend on the sort of different types of bone grafting, quality of donor area and the residual amount of bone left in insertion site. Purpose: the purpose of this study was to evaluate the effectiveness and safety of different types of bone grafts used in maxillary sinus lifting surgeries for implant insertion. Methods: systematic review of randomized clinical trials or quasi-randomized. We used the guidelines of the manual of systematic reviews from Cochrane Collaboration and a sensitive search strategy in three electronic databases has been built. Results: We included six randomized clinical

\footnotetext{
${ }^{1}$ Mestre em Odontologia.

2 Doutorado em Medicina (Nefrologia). Mestrado em Master Of Science In Clinical Epidemiology. Especialização em Especialista Em Nefrologia. Especialização em Residencia Médica Em Clínica Médica e Nefrologia. Graduação em Medicina.
} 
trials from different regions of the world with 135 participants. Bone volume was $3 \%$ higher on the grafted site with autogenic bone pure, but not a statistically significant difference DM: 3 (-8.48-14.48), the average percentage between the vital and non-vital bone showed up $0.82 \%$ higher on the grafted site with FDBA + PRP. The average percentage of vital tissue was also $15.8 \%$ higher on the side where PRP was used. Conclusion: the available evidence is insufficient to recommend a specific type of bone grafting in sinus augmentation (lift) procedures to place a dental implant. There was no statistically significant difference for bone volume, sensory loss, local inflammatory response and loss of implants, among others. For this reason, new randomized controlled trials that evaluate the effectiveness and safety of different types of bone graft for lifting of the maxillary sinus are necessary.

Key-words: Maxillary sinus. Grafting, survey, technique, materials.

\section{INTRODUCTION}

One of the main complaints from partially edentulous patients are the discomfort associated with the wearing of removable dentures, the volume, the aesthetic, the impaired masticatory function and the influence on their social and cultural lives. This is probably one of the reasons why dental implants have became so popular and are in a relevant position as an excellent and promising therapeutic method to obtain an appropriate oral rehabilitation in total and partial posterior edentulous patients minimizing those negative aspects (BALOCH; LENHARO, 2002).

However, its success depends on a minimal amount of bone tissue for implant insertion since after losing teeth the maxillary alveolar process suffers irreversible progressive resorption, resulting in a great loss of substance, both vertically and horizontally and may reach a stage of sinus pneumatization, contraindicating the installation of osseointegrated implants (LIM et al., 2004) that require a minimum $5 \mathrm{~mm}$ alveolar edge thickness and $10 \mathrm{~mm}$ height (MATTE, 2000).

The analysis of the literature has shown and suggested that when there is a sharp maxillary sinus pneumatization and reabsorption of alveolar ridge, sinus craft 
technique introduced by Boyne and James in 1980, quoted by Roldán et al., (2004), associated with bone grafting has gotten predictable and successful results.

Bone grafting allows the reconstruction of anatomy and return predictability to the treatment itself. The bone neoformation occurs by three mechanisms: osteogenesis, osteoinduction and osteoconduction (ABRAHAMS, 2000). Osteogenesis is achieved when the graft is supplied by cells capable of bone formation (osteoblastic cells); osteoinduction is the ability of the graft to stimulate the osteoblastic activity of adjacent bone tissue (receptor bed) with new bone formation and osteoconduction is when mesenchymal differentiation cells invade the graft, promoting the formation of cartilage and then healing (RAGHOEBAR et al., 2005).

The criteria for selection of graft material were determined by the following:

- Bone production potential inside sinus through a cell proliferation of transplanted osteoblasts or by osteoconductive capacity of the cells on the surface of the graft;

-Ability to produce bone by mesenchymal cells osteoinduction;

- Ability of the recently formed bone to develop into mature marrow bone;

-Maintenance of mature bone over time without loss after loading;

-Ability to stabilize implants when simultaneously placed with graft;

-Low rate of infection;

-Easy access;

-Low antigenicity and

-High level of reliability (SPIEKERMANN et al., 2000). 


\section{METHODS}

This study has been conducted according to the guidelines of Cochrane Collaboration Group of Development, Psychosocial issues, and Learning.

The whole methodology is available in the Manual of systematic review of the Cochrane Collaboration (HIGGINS; GREEN, 2005). The study has been approved by the Research Ethics Committee of EPM-UNIFESP, under the ID number 492.

\section{TYPE OF STUDY}

This is Systematic Review of Randomized Clinical Trials or Quasi-Randomized, on the effectiveness and safety of surgical procedure of maxillary sinus lifting using different kinds of grafting materials.

\section{TYPES OF PRIMARY STUDIES}

This review included randomized clinical trials and quasi-randomized. The studies were or were not published as articles, abstracts or letters and there was no restriction to languages.

\section{TYPES OF PARTICIPANTS}

The study included adults who received indication of maxillary sinus lifting surgery aiming implant insertion.

\section{STUDY SELECTION}

Two independent researchers assessed abstracts obtained through electronic and manual searches. One sample has been evaluated by the author and another by Dr. Rachel Riera. A total of 182 articles were fully assessed; the studies were then classified into:

- eligible: a full copy of the article was assessed, and criteria for inclusion applied; 
- Non-eligible: off-topic or studies without control group.

Disagreement in the classification of the studies was discussed at a meeting of consensus among the authors.

\section{EVALUATION OF THE QUALITY OF THE STUDIES}

To ensure that the variance between the groups was not due to systematic errors in methodology, the methodological quality of the selected studies was assessed by two authors independently). Following the criteria described in the Cochrane Collaboration Handbook (HIGGINS, 2006) which is based on evidence of a strong relationship between potential for bias and allocation concealment (SCHULZ, 1995), being defined as:

Low risk of bias: adequate allocation concealment;

Moderate risk of bias: allocation concealment not described in the article;

High risk of bias: inadequate allocation concealment.

\section{STATISTICAL ANALYSIS}

Statistical analysis was performed using the Review Manager software (RevMan), and according to the Manual of systematic reviews from the Cochrane. For dichotomous variables the method of risk ratio (RR) was used, 95\% confidence intervals (random effects model).

For continuous variables, the weighted average difference was calculated (random effects model or fixed effects model), with $95 \%$ confidence interval.

Also, when necessary, the continuous variables were subdivided for dichotomic analysis. Due to interventions and heterogenic results, it has not been possible to gather data and conduct a meta-analysis. 


\section{IDENTIFICATION AND MANAGEMENT OF SELECTED REFERENCES FOR REVIEW}

The search for references was held in 4 databases, in addition to references of relevant studies. All studies that met the inclusion criteria were included.

\section{RESULTS}

The search strategy identified 1680 references, 182 articles were assessed in its entirety and of these, 6 randomized or quasi-randomized articles, fulfilled the inclusion criteria and are analyzed in the review.

These 6 studies evaluated 135 patients. Several outcomes were used in these studies, and the most relevant were: complications in healing; trabecular bone formation; complications of the procedure; signs and symptoms of sinus maxillary diseases; bone volume (one study); insertion of the implant; bone formation for vital and non-vital bone; formation of vital and non-vital bone rate; average percentage of vital tissue (one study); postoperative complications, normal wound healing, sensory loss of cutaneous sensory nerve, bone area percentage average, marked loss of bone density (one study); percentage of average bone area of the section; percentage of deep bone area related to the section; percentage of the average bone section area, peripheral areas of particles; medium-sized particles related to the area of the section; deep particles to the area of the section; average of the particles of the section (one study); maxillary sinus membrane perforation, implant failure or instability at the time of installation; loss of one or more implants, remaining implants removed after 12 months, angled intermediaries, implants with marginal bone loss greater than $2 \mathrm{~mm}$, patients using original prosthetic planning in 12 months.

Barone et al., (2005) evaluated the use of two different materials used in maxillary sinus augmentation, frequently necessary for the implant's placement. Pure autogenic bone and a combination of xenografts from pigs, more specifically using corticocancellous bone materials were used in the study. For the study 18 patients were selected in need of bilateral graft in maxillary sinus. Autogenic bone used was 
from the iliac crest, which has been grafted on one side, named side control, and the autogenic bone combined with pig xenotransplantation has been implanted on the side named -test. To assess the effectiveness of the materials some parameters were chosen by authors such as: complications in healing; trabecular bone formation; complications in the procedure; signs and symptoms of sinus maxillary diseases; bone volume. The authors made notes on the parameters via biopsy performed 5 months after the graft, at the time of implant placement. No complications were observed with respect to healing in neither side grafted and the formation of new trabecular bone also occurred equally on both sides. No complications were reported on either side with different materials, as well as there were no signs and symptoms of sinus maxillary diseases. Only the bone volume showed 3\% higher on the site grafted with pure autogenic bone, but this consideration was insignificant to the authors. Thus, the conclusion is that the graft with the mixture of autogenic bone with osteobiologic bone from pigs is as effective as the use of pure autogenic bone in maxillary sinus augmentation.

Second Kassolis and Reynolds (2005), parameters that could provide data on the effectiveness of the use of different materials were investigated in the study, such as freeze-dried allograft bone (FDBA) platelets rich-plasma (PRP) and the FDBA with absorbable membranes, when used in the maxillary sinus augmentation for subsequent implant placement. Ten patients were assessed requiring bilateral maxillary sinus augmentation, being each side grafted with a distinct material, and no information on the purpose of the treatment, nor inclusion or exclusion criteria and number of implants inserted. The evaluation of the patients was carried out by a technician in histopathology without any knowledge about treatment, and with no possibilities of interfering on the results. Evaluation data collected after six months of grafts placed together with implants, included the vertical dimension from sinus floor to bone crest, by the time of implant insertion; bone formation for vital and non-vital bone; rate between the formation of vital and non-vital bone; average percentage of vital tissue. It was noted that the side grafted with FDBA + PRP had a vertical dimension from the alveolar crest to the floor of the maxillary sinus $0.7 \%$ less than the side grafted with FDBA and restorable membrane; the average percentage of vital bone was $6.8 \%$ 
higher on the grafted with FDBA + PRP, as well as the average percentage of non-vital bone, which also was higher, at $15.8 \%$ on the previously quoted. Thus, the average percentage between the vital and non-vital bone showed up $0.82 \%$ higher on the grafted with FDBA + PRP. The average percentage of vital tissue was also $15.8 \%$ higher on the side where PRP was used. The authors concluded that the combination of FDBA with PRP is more favourable to vital bone formation in the lifting of the maxillary sinus when compared with the graft and resorbable membrane FDBA (KASSOLIS E REYNOLDS, 2005).

Artzi et al., (2005) demonstrated that the jaw bone graft graft in maxillary sinus lifting is an indispensable procedure when placing implants in patients requiring bilateral intervention. This study aimed to evaluate the ability of osteoconduction of two different materials used as bone graft in maxillary sinus augmentation-BBM (bovine bone mineral + autogenic cortical bone fragments from the jaw) and beta-tricalcium phosphate, $\beta$-TCP-with autogenic mandibular cortical bone fragments. For the study 12 patients, seven female and five male were selected ages varying between 42 and 64 years (mean age 50.1 years), and no defined criteria for inclusion or exclusion. According to the authors, the patients did not present any specific health disorder and did not use any medication routine. The study lasted 18 months, the implants were placed after 6 months maxillary sinus augmentation, and samples for evaluation were obtained on the 12th month, being analyzed through histological and histomorphometric methods. The parameters chosen by the authors in this study were: percentage of peripheral bone sectional area; percentage of average bone area of the section; percentage of in the deep region related to the section; the average percentage of bone in the area of the section; peripheral particles of the section areas; medium-sized particles to the area of the section; deep particles to the area of the section; the average of particles of the section. The average percentage of peripheral bone sectional area was $9.9 \%$ higher on the grafted with BBM, which also featured $15.7 \%$ more bone area section in comparison beside grafted with $\beta$-TCP. The amount of bone in the deep region of the sectional area also proved to be larger on the grafted with BBM (15.5\%), the same way with the average bone of sectional area (13.6\%) in comparison to the side with tricalcium phosphate. In the case of particles present in 
sectioned areas, peripheral particles were $1.3 \%$ more on the grafted with $\beta$-TCP compared to BBM, which was also observed with respect to the medium particles, $1.4 \%$ lower in the region grafted with BBM. In the case of deep particles to sectional area, they were $0.6 \%$ more in the region with BBM, and the average percentage of the average number of particles of the areas sectioned was $0.7 \%$ more in the region with grafted tricalcium phosphate. The evaluators concluded that after 12 months of maxillary sinus lifting with the two materials, both promoted new bone formation, however, significantly higher on the grafted with BBM. The display of residual particles at graft proved to be equivalent in relation to the two materials.

According Szabó et al., (2005) the purpose was to evaluate the use of two distinct materials - Cerasorb and autogenic pure bone - in maxillary sinus lifting in patients who needed the bilateral procedure for implants insertion in order to assess whether the use of Cerasorb could decrease the risk of graft donor site morbidity. The sample was composed of 20 patients, and the inclusion criteria was selection of edentulous patients, and exclusion criteria was identifying diseases that could influence the outcome of the treatment. Patients age ranged from 38 to 67 years of age (mean = 52), and all of them had problems in conventional prosthesis retention due to alveolar ridge atrophy in the anterior and posterior regions of the maxilla. Furthermore, bone loss has been identified at level III to IV in three patients, level seven 5 in seven patients and $\mathrm{V}$ to $\mathrm{X}$ in 10 patients. The authors reported that the two materials were grafted in 20 patients, being the side grafted with autogenic bone called the control side and the side with tricalcium phosphate called test side. The study lasted 6 months, and the material collected after that period at the time of implant placement. The data evaluated included: postoperative complications, noted as absent on both grafted sides; normal healing of the wound, which occurred in a satisfactory manner in all 20 patients, on both sides and, therefore, the authors decided not to illustrate in graphics; the cutaneous sensory nerve sensory loss, which occurred in 1 patient on the grafted side with autogenic bone, being this occurrence found non-significant by the authors; average percentage of bone area, which proved to be $1.87 \%$ greater on the control side; severe loss of bone density, which demonstrates $11.18 \%$ of occurrence in the test side. The local inflammatory reaction was $3.15 \%$ greater in the test side, which 
was also considered non-significant by the authors. The total height of the graft was $8.20 \%$ higher on the grafted side with Cerasorb compared to control side. The test side, grafted with Cerasorb, showed a slower bone growth of $8.2 \%$ when compared to the control side, grafted with autogenic bone. The control side showed an average percentage of resorption of the grafted area $5.48 \%$ greater than the test side. The results enabled the authors to conclude that the graft side with b- tricalcium phosphate is effective, even if it's not mixed with autogenic bone.

The study of Wiltfang et al., (2003) aimed assessing whether the graft held with $\beta$-TCP enriched with PRP promotes greater integration and bone degradation when compared to pure $\beta$-TCP graft.The sample was composed of 35 patients, whose blood concentration of thrombocytes was in normal levels; supposing none of them would present sinus membrane perforation. The average age was 46 years, being 27 female and 8 male, bone height prior to surgery of the 2 to $7 \mathrm{~mm}$. Pure $\beta$-TCP was grafted on 18 patients and $\beta$-TCP with PRP in 17 patients, being the chosen parameters evaluated through radiograph taken moments before the insertion of the implants, after six months. The implant sites in both groups allowed for the installation of two or three implants (treated surface of different systems and diameters up to $4 \mathrm{~mm}$ ) in the posterior region of the maxilla. Similarly, the two groups succeeded in full osseointegration after implant insertion and for this reason, have not been illustrated in charts. Healing was successfully in both groups, with no signs of abnormal infections or swelling in any of the components of both groups and were not plotted on forest plot graphs, either. From this, the authors concluded that adding PRP to $\beta$-TCP to bone grafting do not optimize osseointegration and degradation of the graft and neither implants placement.

The study of Wanfors et al., (2000) intended to compare the effectiveness and success of implementation of the maxillary sinus lifting procedure with implant placement in one or two stages, since individual risk of implant failure is twice as large when procedure is a single stage one. To the authors, there is greater risk of crashes when the implant is placed in non-grafted sites. The study has been conducted with 40 patients, being criteria for inclusion, the existence of maxillary sinusitis; the class $\mathrm{V}-\mathrm{VI}$ in the posterior 
region and class III-IV in the anterior region; the presence of residual bone below the maxillary sinus in size from 2 to $7 \mathrm{~mm}$; the age below 80 ; the absence of sinus pathology proven by clinical or radiographic diagnosis and the absence of bone diseases and identification of the use of drugs that could change bone metabolism. Average age was 55 years of age, being 28 females and 12 males; 16 patient's smokers; 10 with bruxism habits and 12 edentulous patients for more than 10 years. The intervention was carried out as follows: 20 patients were grafted and received implants in one phase and 20 patients had the procedure in two stages. The evaluation parameters used to assess the effectiveness were: maxillary sinus membrane perforation; implant failure or instability at the time of installation; loss of one or more implants; remaining implants removed after 12 months; angled intermediaries; refusal of patients by radiographic examination parameters; refusal of patients through radiographic examination in 12 months; bridges replaced by ovendentures; implants with marginal bone loss greater than $2 \mathrm{~mm}$; patients using original prosthetic planning in 12 months. Perforation of sinus membrane was $0.9 \%$ bigger than in procedures performed in 2 stages, not being regarded as a significant result for the authors. About the flaws related to the implant instability by the time of placement of the intermediary, was $1.53 \%$ greater in the procedure carried out in a single stage, in sites with graft, and $2.75 \%$ in non-grafted places on the procedure performed in single-stage. About the failure of the implants in the 12 -month period, $5.15 \%$ more failures occurred in single stage grafts and $0.94 \%$ in sites not grafted in a single-stage, compared to the two-stage procedure.

Implant loss was $1.33 \%$ greater in the procedure done in single-stage. And $5.15 \%$ more residual implants were removed after 12 months in patients where the procedure was performed in a single stage. Angled intermediaries were $2.67 \%$ more present in procedures made in single stage. No patients were refused by radiographic parameters among those in which the procedure was done in two stages, unlike the procedure on a single stage, in which 2 patients were refused. The same occurred with patients evaluated by $x$-ray after 12 months, those who went through the two-stage procedure were not refused. Among those who did the procedure on a single-stage, only 1 was refused. About the replacement of fixed prostheses by ovendentures, the 
fact occurred in only one patient of the two stages group, being this result not significant to the authors. And 3.09\% more patients in whom the procedure was done at one stage had implants with marginal bone loss greater than $2 \mathrm{~mm}$. Also, $0.9 \%$ more patients who received a two-stage procedure remained with the original plan after 12 months of the conclusion. The authors ' conclusion from these results was that some chosen parameters cannot be used for that assessment, but others have shown that the procedure done in two stages is more satisfying to patients.

\section{DISCUSSION}

Grafting of the maxillary sinus surgery requires a very broad and precise anatomic knowledge of upper jaw region because of the its close relation to very important anatomical structures (JAYME; ABUTARA, 2003; TOGASHI, 2002; KATO, 1998) and the specific features of this region, especially the poor bone quality with a thin cortical layer and a thinner bony trabeculae. (FUGAZZOTTO; VLASSIS, 1998).

Despite access to the maxillary sinus being avoided during dental procedures (MANSO; VELLOSO, 2001), the local access procedure, used in surgeries with restricted indications so far (CASALECHI et al., 2006) has undergone many changes, especially after the use of grafting in the maxillary sinus with prosthetic purpose (PASTOR, 1993).

Crest incision on the edentulous ridge and vertical vestibular relaxing incisions (MISCH, 2000), transillumination on palatal surface to optimize identifying maxillary sinus anatomical boundaries (SOLTAN; SMILER, 2005) and the use of membranes within access to the maxillary sinus that expand bone formation (WALLACE et al., 2005; REISER et al., 2001) and, as Werneck (2007), also increase the survival rate of implants, being good examples of these changes.

Based on several studies used as support in this work, we conclude that the autogenic bone graft in the maxillary sinus is considered a safe surgical technique, reliable and with excellent scores of successes, when the goal is the placement of longer implants 
creating better conditions for placing them in posterior jaw regions (EMMERICH et al., 2005; LUNDGREN et al., 2004; PELEG et al., 2004).

However, there are numerous therapies options in which grafting is not used in the maxillary sinus. Barone et al. (2005) found a survival rate of $99 \%$ after one year of follow-up for implants installed with 3, 3 $\mathrm{mm}$ in diameter and height of residual alveolar edge less than $10 \mathrm{~mm}$ in individuals who have not undergone any prior grafting procedures in the maxillary sinus.

Kassolis and Reynolds (2005), comparing the rehabilitation with the use of implants in patients who have undergone grafting in the maxillary sinus prior to installation of implants with those who were not submitted to this technique have found a lower rate of success in jaws with severe resorption, and after 3 to 5 years of monitoring the success rate was higher in the group that did not carry out grafts.

Wannfors et al.,(2000) also found a lower failure rate for implants installed in not grafted areas, and there were not found differences between late or immediate implant installation.

Muronoi et al., (2003), however, when comparing individuals who were submitted to block bone grafts in the maxillary sinus with others that did not, could not record significant differences between the two groups in relation to prosthetic complications. Magini et al., (2006), performing similar comparisons found similar survival rates for implants placed in edentulous jaws with and without graft.

A contraindication for implant therapy, smoking is a controversial topic in literature. Many authors indicate its overuse as detrimental to this type of technique and therefore to the survival rate of the implants installed in grafted maxillary sinuses (BARONE et al., 2005).

However, Peleg et al., (2004), conducting research with follow-ups of 9 years in 226 smoking patients with 627 with dental implants and a success rate of $97.9 \%$, showed that following certain rules such as a protocol of temporary interruption of smoking and the use of at least $50 \%$ of autogenic bone graft, are extremely important to the results 
achieved. When surgical complications are to be discussed, perforation of the sinus membrane is considered the most frequent one (SZABO et al., 2005).

The existence of septa in the interior of the maxillary sinus is an important finding, and may often relate to these incidents, and their existence reported in $30 \%$ of patients (HOROWITZ, 1997).

The repair of perforation of sinus membrane by collagen membrane emerges as a safe and efficient method, not interfering in the success rate of implants (WILTFANG et al., 2003). In bigger perforation, the use of a bone block is an alternative to interruption of the surgery, preventing particles migration into the maxillary sinus, among other advantages (KAUFMAN, 2003).

Summers (1994), noted that membrane excessive stress can cause an accumulation of secretion due to a limitation of transportation capacity by the sinus membrane toward the ostium.

In relation to the effects on the physiological performance of grafting procedure in the maxillary sinus in patients with no signs of sinusitis Timmenga et al. (2003) found no clinical significance. Complications in the donor sites for obtaining the autogenic bone are the occurrence of paresthesia in the jaw and the iliac crest (NKENKE et al., 2002), bleeding, swelling, bruising and a long period of morbidity are some of the complications related to these donor areas (MISCH, 2000).

In relation to immediate or delayed implant placement, avoiding a second surgical procedure and decreasing treatment time, architecture and bone quality such as density and a minimum height of $5 \mathrm{~mm}$ and bone thickness of $4 \mathrm{~mm}$ is a factor of paramount importance (KAUFMAN, 2003). 


\section{CONCLUSION}

\section{IMPLICATIONS FOR PRACTICE}

There is not enough evidence to recommend a specific type of bone graft to fill sinus during the insertion of dental implantation. Until the end of this study, it was not possible to observe statistically significant differences in bone volume, sensory loss, local inflammatory reaction, loss of implants among other aspects. However, the combination of allogeneic freeze-dried rich plasma platelet bone proved to be favourable to vital bone formation in maxillary sinus lift procedure, when compared to grafts with allogeneic freeze-dried bone combined with absorbable membrane.

On the other hand, bone growth in deep region was greater on the grafted region with bovine bone mineral combined with fragments of cortical bone of the mandible when compared to autogenic cortical bone graft fragments and the beta-tricalcium phosphate.

\section{IMPLICATIONS FOR RESEARCH}

In the absence of appropriate studies for this systematic review, new and randomized controlled trials are necessary to investigate relevant outcomes, for example: bone formation, insertion of implants and adverse events, as well as to consider different grafting techniques, long periods of recovering and individual characteristics on which is included the area to be reestablished.

\section{REFERENCES}

ARTZI, Z. et al. A quantidade de osso recentemente formada no procedimento de enxerto sinusal depende da profundidade do tecido bem como do tipo e da quantidade de resíduos do material de enxerto. Clin Periodontol., v.32, n.2, 2005, p.193-199.

BARONE, A. et al. Maxillary sinus augmentation: histologic and histomorphometric analysis. Int J Oral Maxillofac Implants, v.20, n.4, jul/ago, 2005, p.519-525. 
BOYNE, P.J. et al. Bone induction by recombinant human bone morphogenetic protein-2 (rhBMP-2) in maxillary sinus floor augmentation. J Oral Maxillofac. Surg., v.63, n.12, dez 2005, p.1693-1707.

CASALECHI, V.L.; CARDOSO, G.R.; COSSE, L.R. Levantamento do assoalho do seio maxilar: contornando dificuldades. X Encontro Latino-am de Iniciação Cient e VI Enc. Latino Am. Pós-Graduação. Universidade Vale do Paraíba. 2006, p.803-808.

EMMERICH, D. et al. Sinus floor elevation using osteotomes: a systematic review and meta-analysis. J Periondotol., v.76, n.8, ago 2005, p.1237-1251.

FUGAZZOTTO, P.A.; VLASSIS, J. Long-term success of sinus augmentation using various surgical approaches and graftings materials. Int. J Oral Maxillofac. Implants., v.13, n.1, 1998, p.52-57.

HOROWITZ, R.A. The use of osteotomes for sinus augmentation at the time of implant placement. Compend Contin Educ Dent, v.18, n.5, 1997, p.441-451.

JAYME, S. \& ABUTARA, F.H. Princípios da enxertia em seio maxilar: revisão de literatura. Rev. Bras. Implantodont. Prótese Implant., v.10, n.40, out/dez 2003, p.341-345.

KASSOLIS, J.D. \& REYNOLDS, M. A. Evaluation of the adjunctive benefits of plafeletrich plasma in subantral sinus augmentation. J. Craniofac. Surg., v.16, n.2, mar 2005, p.280-287.

KAUFMAN, E. Maxillary sinus elevation surgery: an overview. J. Esthet. Restor. Dent., v.15, n.5, 2003, p.272-283.

KATO, S.T. Avaliação dos tipos de enxerto ósseo e seus homólogos para aumento de rebordo alveolar e levantamento de seio maxilar. Tese [Especialização em Odontologia]. UFMG. Belo Horizonte. 1999, 53p. 
LUNDGREN, S. et al. Bone reformation with sinus membrane elevation: a new surgical technique for maxillary sinus floor augmentation. Clin. Implant. Dent. Relat. Res., v.6, n.3, 2004, p.165-173.

MANSO, M.C. \& VELLOSO, G.R. Instalação imediata de implantes rosqueados em seios maxilares extremamente pneumatizados. Rev. Bras. Implant., v.7, n.4, out/dez, 2001, p.8-12.

MISCH, C.E. Implantes dentários contemporâneos. São Paulo: Santos, 2000.b.

MURONOI, M. et al. Simplified procedure for augmentation of the sinus floor using a haemostatic nasal ballon. Br. J. Oral Maxillofac. Surg., v.41, n.2, 2003, p.120-121.

NKENKE, E. et al. The endoscopically controlled osteotome sinus floor elevation: a preliminary prospective study. Int. J. Oral Maxillofac. Implants., v.17, n.4. 2002, p.557-566.

PASTORI, E.J. Implantes osseointegrados. Sistema implantario: seno maxilar e implantes. Rev. Fac. Odontol., v.13, n.34, 1993, p.90-100.

PELEG, M. et al. Maxillary sinus and ridge augmentations using a surface derived autogenous bone graft. J. Oral Maxillofac. Surg., v.62, n.12, dez 2004, p.1535-1544.

REISER, G.M. et al. Evaluation of maxillary sinus membrane response following elevation with the cristal osteotome technique in human cadavers. Int. J. Oral Maxillofa.c Implants., v.16, n.6, 2001, p.833-840.

SOLTAN, M.; SMILER, D.G. Antral membrane ballon elevation. J. Oral Implatol., v.31, n.2, 2005, p.85-90.

SUMMERS, R.B. A new concept in maxillary implant surgery: the osteotome techinique. Compend. Contin. Educ. Dent., v.15, 1994, p.152-158.

SZABO, G. et al. A prospective multicenter randomized clinical trial of autogenous bone versus beta-tricalcium phosphate graft alone for bilateral sinus elevation: 
histologic and histomorphometric evaluation. Int. J. Oral Maxillofac. Implants, v.20, n.3, maio/jun 2005, p.371-381.

TIMMENGA, N.M. et al. Maxillary sinus floor elevation surgery a clinic radiographic and endoscopic evaluation. Clin. Oral Implant. Res. Munksgaard., n.14, 2003, p.322328.

TOGASHI, A.Y. Antroplastia associada a enxerto ósseo autógeno e colocação imediata de implante osseointegrado: relato de caso clínico. Rev. Bras Implant., v.8, n.4, out/dez, 2002, p.36-38.

WALLACE, S.S. et al. Sinus augmentation utilizing anorganic bovine bone (Bio-oss) with absorbable and nonabsorbable membranes placed over the lateral window: histomorphometric and clinical analyses. Int. J. Periodontics Restorative Dent., v.25, n.6, 2005, p.551-559.

WANNFORS, $\mathrm{K}$. et al. A prospective randomized study of 1 and 2 stage sinus inlay bone grafts: 1 year follow-up. Int. J. Oral Maxillofac. Implants, v.15, n.5, set/out 2000, p.625-632.

WERNECK, J.T. Enxerto em seio maxilar com hidroxiapatita e PRP. Monografia [Especialização em Odontologia]. Academia de Odontologia do Rio de Janeiro. Rio de Janeiro. 2007.66p.

WILTFANG, J. et al. Sinus floor augmentation with beta-tricalcium phosphate (betaTCP): does platelet-rich plasma promote its osseous integration and degradation? Clin. Oral Implants. Res., abr. 2003, v.14, n.2, p.213-218.

Submitted: March, 2020.

Approved: March, 2020. 